\title{
Ultrasound in sacroiliitis: the picture is shaping up
}

\author{
Marwin Gutierrez $^{1,2} \cdot$ Carlos Pineda $^{1}$
}

Received: 20 October 2017 / Accepted: 21 October 2017 / Published online: 30 October 2017

(c) Springer-Verlag GmbH Germany 2017

Keywords Sacroiliitis · Ultrasound · Diagnosis

\section{Introduction}

Currently, ultrasound (US) has become a reference tool for many rheumatologists to assess a wide range of rheumatic and musculoskeletal diseases. Its potential to provide valuable information in different clinical and research scenarios including diagnosis, differential diagnosis, treatment monitoring, guidance during clinical procedures and evaluation of disease remission is well recognized [1-6].

In recent years, the use and applications of US in rheumatology have expanded; we now know that it can be useful for the assessment of anatomical targets beyond the musculoskeletal system. US is demonstrating solid evidence of its validity in the study of salivary glands, medium and large size vessels (carotid, temporal arteries, aorta), skin, nails and lung in rheumatic diseases [7-10]. These new applications of US are opening-up the concept of "systemic ultrasound in rheumatology".

In spondyloarthritis (SpA), US has already accumulated a wealth of evidence. This is supported by the inclusion of their findings in the last EULAR recommendations for the

Carlos Pineda

carpineda@yahoo.com

Marwin Gutierrez

dr.gmarwin@gmail.com

1 Instituto Nacional de Rehabilitación, Luis Guillermo Ibarra Ibarra, Calzada Mexico-Xochimilco 289, Colonia Arenal de Guadalupe, 14389 Mexico City, CP, Mexico

2 Doctorado en Ciencias Biológicas y de la Salud, Universidad Autónoma Metropolitana, Iztapalapa, México City, Mexico diagnosis and management of SpA in clinical practice [11]. Although there are no doubts regarding the US validity to assess peripheral synovitis and/or enthesitis in SpA [12-16], its utility in evaluating sacroiliac joints (SIJs) still generates place for discussion. To elucidate this topic, CastilloGallego et al. [17], in the current issue of Rheumatology International, present a well-conducted and optimally structured study that leads a clear and important message: "Color Doppler US (CDUS) might be the initial imaging technique to study inflammatory low back pain".

This study, worthy of encomium, also merits a detailed analysis to display its correct place in the "state of the art" of US with respect to the assessment of SIJs.

\section{State of the art of US in sacroiliitis}

The ability of US to detect active sacroiliitis was tested back in the earlier 2000. Klauser et al. [18] demonstrated that microbubble contrast-enhanced CDUS was a sensitive technique to detect active sacroiliitis when compared with magnetic resonance imaging (MRI). Interesting, they described how the sensitivity was largely different between unenhanced and contrast-enhanced CDUS (17 versus 94\%, respectively). These results should be interpreted on the light of the availability, invasiveness and costs of contrastenhanced CDUS. From the economic perspective, the costs of contrast-enhanced CDUS were estimated to be less than one third of that for contrast-enhanced MRI [18]. Although its application could reduce the number of MRI studies in inflammatory low back pain patients, it remains still expensive if we compare the cost-effectiveness with respect to conventional US. Some years ahead, the same author showed as the sensitivity and specificity may be superior in detecting active sacroiliitis (both 100\%) using a second-generation 
contrast agent with respect to healthy subjects [19]. However, the barrier of the costs is still palpable.

The relevance of the study of Castillo-Gallego et al. [17] is supported by the fact that, in contrast with the previous studies, they found adequate accuracy for the conventional CDUS findings in the detection of active sacroiliitis (sensitivity $70.3 \%$; specificity $85.7 \%$ ) with the possibility to increase them to 76.2 and $77.8 \%$, respectively, if the resistance index (RI) technique was used. Although the comparator in the study of Castillo-Gallego was the physical examination, as in the majority of studies, the results are of interest to revisit the issue of US in sacroiliitis. It is remarkable in the study that any Doppler signal present within SIJs was integrated with the measurement of RI, which support more strongly the presence of an inflammatory vascularization pattern inside the joint. Moreover, the authors propose a cut-off value for the RI $(\leq 0.75)$ that permits differentiate clinical activity from normality using flow pattern assessment. The message is clear again, to increase the accuracy of US findings seems mandatory to use RI measurements.

The assessment of SIJs by US includes also the assessment of morphostructural changes in grayscale, such as width of SIJs capsule and sacrotuberous and longus posterior sacroiliac ligament thickness. Baldinelli et al. [20] compared these US findings with those of clinical and X-ray in early SpA patients. Both SIJs width and sacrotuberous ligament thickness showed to be superior in early SpA patients, whereas posterior sacroiliac ligament thickness was similar in SpA and healthy controls. With respect to physical examination and X-ray findings, US showed to be more sensitive for the detection of joint and soft tissue peri-articular involvement at SIJs level. Spadaro et al. [21] conducted also a study including grayscale findings (effusion) showing a statistical difference in terms of effusion, being more frequent in SpA patients than healthy controls. The sensitivity of US for the assessment of SIJs was 79\%, whereas the specificity was $71 \%$.

Jiang et al. [22] explored the potential of power Doppler (PD) US to assess the sensitivity to change at SIJs level after anti-TNF treatment in ankylosing spondylitis (AS) patients. The US follow-up was performed 12 weeks after starting the biological treatment and included the RI study to confirm PD findings. All patients showed a decrease of both, PD signal and the average RI value. This is a study that demonstrates as US may be a useful tool to detect changes after treatment at SIJs level.

\section{Paradigms and futures perspectives of US as tool for the assessment of SIJs}

To date, there are still few studies advocated to investigate the potential use of US to detect active sacroiliitis in patients with inflammatory low back pain. Additionally, most of them showed significant differences in the conception of study design.

The first barrier for a routine use of US in the assessment of SIJs is the lack of consensus regarding the standardization of both, the technique and the machine settings to adequately explore this complex anatomical structure. The latest is an important obstacle because SIJs are located in a deep anatomical position surrounded by important ligaments and muscular mass, which can impair the visualization of the entire joint. In fact, most of studies have mainly described the US visualization of the superior/proximal one third of the SIJs. Thus, frequently remain unexplored the medial and inferior/distal one third of the joint where may start the inflammatory process in SIJs, especially in early stages of the disease process.

To determine the activity of inflammatory process at SIJs level, it is necessary to use US techniques that evaluate the vascularization inside the joint $[17,22,23]$. Here, there is an another issue that needs more work by the experts. There is no consensus regarding how should be assess the vascularization (by PD, CD, spectral Doppler, calculation of RI?) and how it might be quantified (quantitative or semiquantitative method?) [18, 19, 22, 23].

As Castillo-Gallegos et al. mentioned, close to the SIJs, there are different sacral foramens that contain vessels, which may generate confusion at the time of interpretation, inducing especially false positives. Her group showed as the measurement of the RI as mandatory complement of a previous positive Doppler signal increase the accuracy of the finding. Thus, it seems to be the correct approach to minimize the bias of interpretation. However, standardization (settings and techniques) and dedicated training are also mandatory targets. Finally, the limited acoustic window for the sonographic visualization of SIJs does not permit satisfactory grayscale information regarding the presence of erosions, effusion, soft tissues or other morphostructural changes useful to classify the sacroiliitis. In fact, at date, only two studies proposed the assessment of grayscale findings by US [20, 21].

Notwithstanding, future initiatives will undoubtedly solve these gaps; especially strong efforts must be made towards the standardization of the technique (settings, type of transducers and acquisition of images) and interpretation. This point address the priority on educational aspects aimed to uniform the use and application of US in the assessment of SIJs. Additionally, studies exploring the reliability of US findings in SIJs, the concurrent validity (using MRI or histology as reference) and the feasibility in terms of time expend for the US examination of SIJs should be also the milestone of the futures investigations in this topic. CastilloGallego et al. declare that 3-5 min (2 more minutes including spectral Doppler) was sufficient for each examination. It seems to be a good starting point. 
In conclusion, although MRI is still the imaging method of reference for the assessment of inflammatory process and anatomical damage of SIJs, especially in the early stages, CDUS is demonstrating capability to become an additional method for an initial screening of those patients with inflammatory low back pain and clinical suspicion of sacroiliitis.

\section{Compliance with ethical standards}

Conflict of interest The authors declare no conflicts of interest regarding this paper.

\section{References}

1. D’Agostino MA, Terslev L, Wakefield R et al (2016) Novel algorithms for the pragmatic use of ultrasound in the management of patients with rheumatoid arthritis: from diagnosis to remission. Ann Rheum Dis 75:1902-1908

2. Naredo E (2015) Ultrasound in Rheumatology: two decades of rapid development and evolving implementation. Med Ultrason 2015(17):3-4

3. Hammer HB, Kvien TK, Terslev L (2017) Ultrasound of the hand is sufficient to detect subclinical inflammation in rheumatoid arthritis remission: a post hoc longitudinal study. Arthritis Res Ther 4(19):221

4. Allen JC Jr, Thumboo J, Lye WK, Conaghan PG, Chew LC, Tan YK (2017) Novel joint selection methods can reduce sample size for rheumatoid arthritis clinical trials with ultrasound endpoints. Int J Rheum Dis. https://doi.org/10.1111/1756-185X.13185

5. Díaz-Torné C, Moragues C, Toniolo E et al (2017) Impact of ultrasonography on treatment decision in rheumatoid arthritis: the IMPULSAR study. Rheumatol Int 37:891-896

6. Gutierrez M, Filippucci E, Salaffi F, Di Geso L, Grassi W (2011) Differential diagnosis between rheumatoid arthritis and psoriatic arthritis: the value of ultrasound findings at metacarpophalangeal joints level. Ann Rheum Dis 70:1111-1114

7. Mossel E, Delli K, van Nimwegen JF et al (2017) EULAR US-pSS Study Group. Ultrasonography of major salivary glands compared with parotid and labial gland biopsy and classification criteria in patients with clinically suspected primary Sjögren's syndrome. Ann Rheum Dis 76:1883-1889

8. Gutierrez M, Kaeley GS, Bertolazzi C, Pineda C (2017) State of the art of ultrasound in the assessment of psoriasis and psoriatic arthritis. Expert Rev Clin Immunol 13:439-447

9. Germanò G, Monti S, Ponte $\mathrm{C}$ et al (2017) The role of ultrasound in the diagnosis and follow-up of large-vessel vasculitis: an update. Clin Exp Rheumatol 35(Suppl 103):194-198

10. Gutierrez M, Gomez-Quiroz LE, Clavijo-Cornejo D et al (2016) Ultrasound in the interstitial pulmonary fibrosis. Can it facilitate a best routine assessment in rheumatic disorders? Clin Rheumatol $35: 2387-2395$
11. Mandl P, Navarro-Compán V, Terslev L et al (2015) EULAR recommendations for the use of imaging in the diagnosis and management of spondyloarthritis in clinical practice. Ann Rheum Dis 74:1327-1339

12. Falcao S, Castillo-Gallego C, Peiteado D, Branco J, Martín Mola E, de Miguel E (2015) Can we use enthesis ultrasound as an outcome measure of disease activity in spondyloarthritis? A study at the Achilles level. Rheumatology 54:1557-1562

13. de Miguel E, Muñoz-Fernández S, Castillo C, Cobo-Ibáñez T, Martín-Mola E (2011) Diagnostic accuracy of enthesis ultrasound in the diagnosis of early spondyloarthritis. Ann Rheum Dis 70:434-439

14. D'Agostino MA, Aegerter P, Bechara K et al (2011) How to diagnose spondyloarthritis early? Accuracy of peripheral enthesitis detection by power Doppler ultrasonography. Ann Rheum Dis 70:1433-1440

15. Ruta S, Marin J, Acosta Felquer ML, Ferreyra-Garrot L et al (2017) Utility of power Doppler ultrasound-detected synovitis for the prediction of short-term flare in psoriatic patients with arthritis in clinical remission. J Rheumatol 44:1018-1023

16. Wendling D, Aubry S, Prati C (2016) Spondyloarthritis. Clinical versus imaging assessment: and the winner is? J Rheumatol 43:468-470

17. Castillo-Gallego C, De Miguel E, García-Arias M, Plasencia C, Lojo-Oliveira L, Martín-Mola E (2017) Color Doppler and spectral Doppler ultrasound detection of active sacroiliitis in spondyloarthritis compared to physical examination as gold standard. Rheumatol Int. https://doi.org/10.1007/s00296-017-3813-3

18. Klauser A, Halpern EJ, Frauscher F et al (2005) Inflammatory low back pain: high negative predictive value of contrast-enhanced color Doppler ultrasound in the detection of inflamed sacroiliac joints. Arthritis Rheum 15(53):440-444

19. Klauser AS, De Zordo T, Bellmann-Weiler R et al (2009) Feasibility of second-generation ultrasound contrast media in the detection of active sacroiliitis. Arthritis Rheum 15(61):909-916

20. Bandinelli F, Melchiorre D, Scazzariello F, Candelieri A, Conforti D, Matucci-Cerinic M (2013) Clinical and radiological evaluation of sacroiliac joints compared with ultrasound examination in early spondyloarthritis. Rheumatology 52:1293-1297

21. Spadaro A, Iagnocco A, Baccano G, Ceccarelli F, Sabatini E (2008) Valesini G. Sonographic-detected joint effusion compared with physical examination in the assessment of sacroiliac joints in spondyloarthritis. Ann Rheum Dis 68:1559-1563

22. Jiang Y, Chen L, Zhu J et al (2013) Power Doppler ultrasonography in the evaluation of infliximab treatment for sacroiliitis in patients with ankylosing spondylitis. Rheumatol Int 33:2025-2029

23. Mohammadi A, Ghasemi-rad M, Aghdashi M, Mladkova N, Baradaransafa P (2012) Evaluation of disease activity in ankylosing spondylitis; diagnostic value of color Doppler ultrasonography. Skeletal Radiol 42:219-224 